\title{
What do positioning paths of universities tell about the diversity of higher education systems? An exploratory study ${ }^{1}$
}

Giovanni Barbato $(*)$ and Matteo Turri $(* *)$

(*) Department of Economics, Management and Quantitative Methods, Università degli Studi di Milano, Milan, Italy.

(**) Department of Economics, Management and Quantitative Methods, Università degli Studi di Milano, Milan, Italy.

Corresponding author: Barbato Giovanni: giovanni.barbato@unimi.it; Department of Economics, Management and Quantitative Methods (DEMM), Università degli Studi di Milano, Via Conservatorio 7, 20122, Milan, Italy.

${ }^{1}$ The article is published in Studies in Higher Education 


\title{
What do positioning paths of universities tell about the diversity of higher education systems? An exploratory study
}

\begin{abstract}
Diversity in Higher Education system has been a central topic for both scholars and policy-makers for decades. Several studies have investigated how to measure diversity and the nature of its determinants so far; however, contradictory empirical evidence has emerged. This paper contributes to this literature by adopting a methodological approach that starts from the analysis of positioning paths of Higher Education Institutions (HEIs) in order to explore the diversity of HE systems. A comprehensive quantitative analysis performed across two HE systems over time shows how detecting the positioning of HEIs can provide information that an analysis of diversity at the level of the entire system might hide, in particular (I) if and how compliant and distinctiveness are concurrently displayed (II) in which dimensions positioning shifts are more likely to occur and (III) which groups of HEIs influence more the level of diversity in a HE system.
\end{abstract}

Keywords. positioning, positioning indicators, diversity, cluster analysis, distance measure, higher education

\section{Introduction}

Diversity of Higher Education systems has been a central topic in Higher Education (HE) literature since the 1970s and can be defined as the variety of Higher Education Institutions (HEIs) within a HE system (Neave 1979; Birnbaum 1983; Codling and Meek 2006; Huisman et al. 2007). Diversity has been widely investigated since it is claimed that a diversified HE system is an inherent good for the economy and society of a country (Goglio and Regini 2017), even if these positive effects are still debatable (Van Vught 2008).

However, empirical evidence on the determinants (institutional pressures, competition) and outcomes of diversity has been rather contradictory with distinctive patterns highlighted in highly institutionalized contexts (Kraatz and Zajac 1996; Bonaccorsi and Daraio 2007; Rossi 2009) and convergence processes found in increasing competitive contexts, where a growth in diversity was expected (Goedegebuure et al. 1993; Rossi 2010).

Based on this mixed evidence, some scholars started to argue how investigating positioning of HEIs can enhance the understanding of the diversity of HE systems (Daraio et al. 2011; Fumasoli and Huisman 2013; Huisman et al. 2015). This argument will be the main focus of this paper. Institutional positioning can be defined as 'the process through which HEIs locate themselves in specific niches within the HE system' (Fumasoli and Huisman 2013, 160). The niche reflects the activities (teaching, research, third mission) and resources (e.g. financial, human) in which the HEI can prosper as well as the potential relations (competition, cooperation) with the others HEIs that 
share the same position or a similar position. Ultimately, the positioning of a HEI tells what and how that institution does compared to the other institutions in the same HE system.

How positioning affects diversity might seem quite trivial initially. If all the HEIs are located in the same position the diversity of HE systems is low while if different niches are occupied diversity increases. However, scholars claimed how HEIs can respond to the same environmental pressures differently (Oliver 1991; Paradeise and Thoenig 2013) and heterogeneous positioning paths can be potentially undertaken. Investigating how HEIs position themselves can help to disentangle diversity of the HE systems, e.g. by detecting if convergent and differentiating processes occur simultaneously and which of these processes impact more on the level of diversity over time. Moreover, the analysis of how HEIs combine several activities/resources of the niche, and how this mix changes over time, sheds light on which dimensions HEIs tend to appear more either distinctive or similar. Finally, the analysis of positioning can also reveal which groups of HEIs influence more on the level of diversity of the HE system by displaying a more distinctive pattern. In other words, investigating positioning allows considering some of the heterogeneity that an analysis of diversity, at the level of the entire HE system might hide.

The aim of this paper is to show the importance of investigating the institutional positioning of HEIs over time and how this can improve our understanding of the diversity of HE systems. Moreover, empirical studies on institutional positioning have been mainly concentrated on detecting distinctive positioning efforts by analysing mission statements and strategic plans (Mampaey et al. 2015; Seeber et al. 2017; Morphew et al. 2018). There are instead fewer empirical studies focused on how to analyse positioning quantitively (exceptions are e.g. Bonaccorsi and Daraio 2007, 2008; Bonaccorsi 2009; Ljungberg, Johansson and McKelvey 2009; Cattaneo et al. 2018). This article also intends to start bridging this gap by analysing how HEIs position themselves in two countries quantitively and longitudinally. The focus of the article is thus on how - instead of why - HEIs position themselves since its research goal is more of a methodological nature.

The paper is structured as follows. Section 2 illustrates in theoretical terms why and how positioning can affect the diversity of HE systems. Section 3 describes the data and the quantitative methods used to investigate positioning. The findings are then presented in Section 4 and discussed in the final section.

\section{Why and how Positioning of HEIs might affect Diversity of HE Systems}

Neo-institutionalism and the Strategic perspective are the two main theoretical perspectives that have been employed to investigate institutional positioning and diversity in HE (Fumasoli and Huisman 2013). Both perspectives make specific assumptions about the nature and goals of HEI as 
an organization (I) and the relationship between environmental pressures and the responses of HEIs to them (II). By focusing on these two dimensions the potential links between positioning and diversity are highlighted.

In relation to the first dimension (I), Neo-institutionalism and the Strategic Perspective approach claim the gain of legitimacy and the need of distinctiveness to be the ultimate goals of the organizational agency. Legitimacy can be defined as 'a generalized perception or assumption that the actions of an entity are desirable, proper, within some socially constructed system of norms [...]' (Suchman 1995, 574-575). As legitimacy-seeking entities, HEIs are heavily influenced by the exogenous pressures since conformity towards them provide resources and ultimately survival (Van Vught 2008). Since HEIs operate under the same isomorphic pressures, they will consequently resemble each other, and diversity of HE systems has no other possibility but to decrease (Neave 1979; Morphew 2009). Therefore, positioning efforts consist in a more or less passive adaptation in the direction indicated by these external forces (Fumasoli and Huisman 2013).

On the contrary, a strategic perspective assumes HEIs to have some scope for strategic agency, so that positioning is the result of a deliberate or emergent strategy (Bonaccorsi and Daraio 2007; Fumasoli and Lepori 2011). Only distinctiveness from competitors assures survival since it enables HEIs to position themselves in exclusive niches of resources (Porter 1985).

However, scholars increasingly demonstrated how legitimacy and distinctiveness can be pursued concurrently by HEIs since these are both relevant for them (Fumasoli and Huisman 2013; Mampaey et al. 2015). Empirical studies evidenced how positioning is often more a 'balance' between legitimacy-seeking and distinctiveness-seeking behaviours (Pedersen and Dobbin 2006; Seeber et al. 2017; Morphew et al. 2018), in order to be 'as different as legitimately possible' (Deephouse 1999, 47).

Hence, since the positioning of a HEI expresses how several activities and other factors are combined into a unique position, the analysis of positioning highlights first of all in which dimensions of the niche HEIs tend to converge or to differentiate themselves over time, highlighting the presence of polarization or imitating trends. Secondly, it allows us to verify if HEIs are striving to appear both distinctive and similar and in which ways they tend to do it.

As regards the relationship between environmental forces and HEI's actions (II), Neoinstitutionalism and the Strategic Perspective approach look at institutional pressures and competition as the main forces that influence the behaviours of HEIs (Fumasoli and Huisman 2013). Institutional pressures can be represented by government regulation whereas competition can be material (students, researchers, funds) and non-material (reputation). As underlined by Fumasoli and Huisman (2013, 156), empirical studies informed by these two theoretical frameworks have 
often assumed that HEIs respond uniformly to isomorphic pressures and competition by displaying either conformity or distinctive behaviours, even if this is not empirically established yet and with contradictory empirical evidences (Rossi 2010). Consequently, most of these studies looked at the level of the whole population (the HE system) while few papers look at institutional responses to these pressures (exceptions are e.g. Maassen and Potman 1990; Kraatz and Zajac 1996; Cattaneo et al. 2018).

However, there are also papers informed by the same theoretical perspectives mentioned above that started to reappraise the level of the HEI as a fruitful level of analysis which allow to understand why and how HEIs can respond to the same environmental pressures differently (Oliver 1991; Frølich et al. 2013; Paradeise and Thoenig 2013). The Scandinavian school of Neo-institutionalism, for example, developed the so-called 'Translation theory', which focuses on the fact that environmental pressures are internalized by organizations through the perceptions of their members, based on a common historically constructed identity, so that these macro-level ideas can be adjusted to local organizational settings (Sahlin and Wedlin 2008). Since translation processes are unique, these can generate a combination of heterogeneous responses from HEIs (Mampaey et al. 2015; Silander and Haake 2016). Other papers focused on how structural organizational features mediate the relationship between environmental forces and the HEIs' agency, thus affecting the diversity of a HE system (Ljungberg et al 2009; Rossi 2009). In particular, the status of HEIs has been widely investigated to understand why HEIs can deviate from the expected increasing differentiation vis-àvis higher competition (Brewer et al. 2002; Van Vught, 2008; Brankovic 2018). On the one hand, it has been shown how low-status HEIs tend to copy higher-status HEIs to gain legitimacy, even in competitive contexts like the US, Australia and other English-speaking countries (Riesman 1956; Goedegebuure et al. 1993; Codling and Meek 2006; Toma 2012). Competition for prestige is said to be more relevant than that for resources and mimicking more appealing than a more 'rational' differentiation (Van Vught 2008). More recently, Stensaker et al. (2018) and Huisman and Mampaey (2018) proved how differences in status can also lead to some differences in the strategies of HEIs, whereupon low-status HEIs present more distinctiveness and old and high-status institutions are more reluctant to lose an established external recognition.

Analysing positioning paths allows transitioning from the level of the whole population to the local level by including possible behaviours that were not expected theoretically. In addition, it offers the opportunity to include organizational variables that can mediate the expected relationship between a certain environmental pressure and the actions of a HEI and, as a result, point out if specific values are associated with positioning paths that impact more on the level of diversity of the system. In conclusion, investigating the diversity of HE systems by focusing on a lower level of analysis 
(positioning of HEIs) can be beneficial as a more comprehensive picture of the former may arise from the analysis of the latter (Fumasoli and Huisman 2013). Finally, since the aim of the article is not to explain why HEIs change or maintain their positioning over time but to test a methodological approach, the empirical analysis will not focus on the (more or less) strategic purposes of positioning processes but it will just frame how they change over time.

\section{Data and methods}

\subsection{Data and indicators}

In order to study positioning and how it potentially affects diversity, both the level of the HE system and that of the HEI were considered. To assure a meaningful relationship between these two levels of analysis, the same indicators were used in the two empirical investigations. The indicators were chosen according to three criteria.

First, since HEIs are multi-input and multi-output organizations (Bonaccorsi and Daraio 2007), positioning should be investigated on several dimensions that reflect relevant features/activities of HEIs and, therefore, of the niche. Three broad dimensions were identified for this article, i.e. the core functions (teaching, research, third mission), the subject mix (generalist vs specialized) and the market size (international, national, regional) of HEIs. In addition, data on the affiliation of HEIs to mission groups ${ }^{1}$ have also been gathered as this is said to express the status of a HEI (Brankovic 2018).

Second, we drew on previous studies that reached considerable consensus on the most suitable and comparable indicators for studying diversity and positioning (Bonaccorsi and Daraio 2007, 2008; Rossi 2010; Daraio et al. 2011; Huisman et al. 2015).

Lastly, the availability of micro-data influenced the selection of the indicators. Based on these criteria, a list of 8 indicators was identified as illustrated in Table 1.

\section{Table 1}

Data were collected at the level of the single HEI for two HE systems, namely, the Italian and the English, covering the decade from 2004 to 2014 (see Appendix). The final sample consists of 95 English and 58 Italian public HEIs ${ }^{2}$.

These two HE systems allow investigating positioning paths in two contexts with different level of competition but are still comparable. The English HE system presents indeed higher levels of competition as a result of several reforms started in the 1990s which affected, in particular, the funding mechanisms of HEIs (Brown and Carrasco 2013). By contrast, competition is still weak in Italy since the majority of public funding is directly granted from the state (Capano, Regini and 
Turri 2016). Moreover, English HEIs benefit from a high institutional autonomy than Italian HEIs, which certainly has an impact on the actual capacity of HEIs to position themselves distinctively. Despite these differences, both countries have unitary HE systems that are not too dissimilar in terms of number of universities and students, and which present strong institutional pressures in the form of evaluation exercises and QA mechanisms.

In addition, the choice of a HE system (England) which is historically more diverse that the other (Italy) (see Daraio et al. 2011; Huisman et al. 2015) can show whether the analysis of positioning can inform the understanding of diversity, also for HE systems that are less diversified, such as Italy, or positioning is more country-specific; in other words, if it is meaningful only for England.

\subsection{Methods}

Two different quantitative analyses were performed in relation to the two levels of study. At the level of the entire HE system, indicators were used to measure how diversity changed over a decade, by using distance measures. The term diversity is here intended as external and horizontal, in other words, it refers to differences in the type and orientation of activities/resources in HEIs (Huisman et al. 2007; Van Vught 2008). Distance measures were chosen to preserve the richness of continuous indicators (Huisman et al. 2015).

Consequently, the mean sum of Euclidean squared distance (MSSD) (Bonaccorsi 2009) was determined for each indicator for 2004, 2007, 2010 and 2014³. Operationally, the Euclidean distance between each HEI $(i)$ and all other HEIs $(j)$ in the same country and for each indicator $(w)$ was computed and then divided by the mean value of the indicator $(\hat{\mathrm{w}})^{4}$.

The Euclidean distance is considered to be the best measure in the case of a skewed distribution of indicators (Huisman et al., 2015). All the squared distances were then summed and divided by the square of the number of HEIs to enable comparison between the two countries (Bonaccorsi 2009).

$$
M S S D=\left(1 / n^{2}\right) \sum_{i=1}^{n} \sum_{j=1}^{n}\left(\frac{\left(w_{i}-w_{j}\right)}{\hat{w}}\right)
$$

At the level of individual HEIs, two different clustering exercises were performed for each country. Cluster analysis has already been used as a fruitful method to investigate positioning and diversity in HE (Huisman 2000; Huberty, Jordan and Brandt 2005; Rossi 2010; Wang and Zha 2018).

The purpose of the first clustering exercise was to identify groups of positioning based on each indicator (except for the indicator SIZE). For these clusters, the internal distribution in 2004 and how the dispersion of HEIs changed in 2014 was analysed. In this way, positioning paths can be 
classified along the 'conservative' vs 'discontinuous' continuum, by considering whether HEIs changed their position (cluster) more or less distinctively from 2004 to 2014.

The second cluster analysis aimed at investigating the "intensity" of positioning paths, that is the extent of the change in the values of indicators between 2004 and 2014. Intensity is measured by considering the differences between 2004 and 2014 minus the mean of the sample. This last value is used as a benchmark to establish if a positioning path displayed low, medium or high intensity over time. The higher the value was above 0 , the greater the intensity of the positioning path was because its change was above the average change of the sample. A "high intensity" was registered when this difference was one (or more) times higher (or lower, depending upon the indicator) than the mean difference of the sample. The intensity of a positioning path was then classified as "medium" instead of "high" depending upon the number of indicators that has registered a significant change. Both clustering exercises followed the same procedure. First, each indicator was standardized using $\mathrm{z}$ scores since there was no uniform metric (Huberty et al. 2005). Moreover, since the number of clusters cannot be predicted in advance, a hierarchical clustering exercise was performed. The Ward method was used as the algorithm to separate clusters since is claimed to be the best to obtaining distinct clusters (Huisman 2000). Finally, The Duda-Hart stopping rule along with observation of the dendrogram, were then used to identify the best cluster solution (numbers of clusters).

\section{Results}

\subsection{Diversity of the two HE Systems}

Table 2 shows the level of diversity of the two countries and the 8 indicators computed through the mean sum of Euclidean squared distance (MSSD). First, it can be generally stated that the English HE system is more diverse than the Italian across almost all the indicators. Second, Table 2 describes in which dimensions diversity changed over time. The diversity of the English HE system decreased especially in the research dimension where diversity of $\mathrm{PhD}$ ratio and Researcher intensity (ISI) were reduced by almost 50\%. Regarding the Italian HE system, diversity decreased similarly across ISI and SIZE. Both systems have become increasingly heterogeneous in their market scope (international or regional orientation), whereas the educational profile and the subject mix of HEIs remained basically the same.

\section{Table 2}

\subsection{HEIs' positioning in 2004 and 2014}

Clusters of positioning of English and Italian public HEIs in 2004 and 2014 are illustrated in Tables 3, 4, 5 and 6. In relation to the Italian context, three clusters were identified in 2004 (Tab. 3). The 
clusters differed across a relatively small number of indicators, i.e. subject mix, international orientation and third mission orientation. With respect to the other indicators, the clusters are rather homogeneous, thus it is not possible to identify a straightforward polarization between teaching and research orientation.

\section{Table 3}

Table 4

However, a four-clusters solution was identified for 2014 (Tab. 4). Two clusters (1 and 3) can be described as more research-focused than the other two. The difference between teaching and research-oriented clusters is clearer after a decade. Indeed, the number of publications per academics (ISI) of the 'research-oriented' cluster 1, is almost twice as much as the 'teachingoriented' cluster (4) whereas this difference was significantly lower in 2004. Clusters 2 and 4 are more teaching-focused even if their values of PHD and ISI also increase over time and are not excessively below the mean value of the sample. Moreover, clusters 1 and 3 are more internationally oriented than 2 and 4 but still imply a high percentage of regional students. Finally, between 2004 and 2014, 9 HEIs change position in a discontinuous way since they moved from clusters 1 and 3 (Tab. 3) to clusters 1 and 2 in 2014 (Tab. 4). Other 13 HEIs presented some discontinuity even if only for one indicator. 9 HEIs, for example, changed their cluster (3 in 2004) for a similar one (3 in 2014) except for its greater internationalization. Finally, 36 out of 58 HEIs maintained the same positioning over time.

In relation to the English case, HEIs differed on the basis of multiple indicators and this generated a high number of clusters both in 2004 (Tab. 5) and 2014 (Tab. 6). This simply emphasises that the English HE system is more diversified that the Italian HE system. This consideration is further supported by the dendrograms. English dendrograms show a longer vertical line at the top of both graphs. This indicates that the clusters represented by those lines are clearly separated and distinct since they are grouped at higher level of dissimilarity (L2), whereas in the Italian clusters form at lower level of dissimilarity both in 2004 and 2014 (see Appendix for dendrograms).

In 2004, the two 'teaching-oriented' clusters (Tab. 5, 1 and 3) varied also on their subject mix as well as on a more regional vs international orientation. Similarly, the 'research-oriented' clusters (4 and 5) differed based on their subject mix, third mission and international orientation. Furthermore, cluster 2 presented an average value of research intensity (ISI) besides a significant percentage of undergraduates $(75 \%)$.

The six-clusters solution identified in 2014 (Tab. 6) underlined a clearer polarization between research and teaching focused clusters. First, there are no more clusters that have average values of 
research and teaching orientation like 2004's cluster 2. Second, in 2014 'research-oriented' clusters (Tab. 6 clusters 4, 5 and 6) display higher levels of $\mathrm{PhD}$ ratio (PHD), research intensity (ISI) and third mission orientation as well as much lower percentages of undergraduate students compared with 2004's research-oriented clusters (Tab. 5, clusters 4 and 5). In general, this polarization reflects the affiliation of English HEIs to mission groups with the members of Russell and the 1994 in the 'research oriented' clusters both in 2004 and 2014.

Finally, when the positions of HEIs between 2004 and 2014 are compared, we can note that 66 out of 95 HEIs maintained the same or a similar cluster while 14 changed it significantly. HEIs belonging to cluster 2 in 2004 moved into a more distinctive cluster along the research vs teaching continuum in 2014 (clusters 1, 2, 3, and 6). Moreover, these 14 HEIs mainly belong to the Million + group (9), whereas the others present either no affiliation or are members of the University Alliance group.

Other 15 HEIs partially changed their position since they show discontinuity in only one indicator (e.g. some HEIs from cluster 1 in 2004 to cluster 2 in 2014) and only one of them is part of the Russell group.

\section{Table 5}

Table 6

\subsection{HEIs' Positioning paths: differences between 2004 and 2014}

Table 7 and 8 illustrate the clustering exercise on the differences of indicators values between 2004 and 2014 (minus the mean difference of the sample). The identified clusters were then classified according to the intensity of the corresponding positioning paths. 6 types of patterns were identified for English HEIs (Tab. 7). Clusters differed based on two criteria as mentioned in section 3.2. First, they varied according to how many indicators increase relevantly over time (1 or more time higher than the average difference). Second, clusters differed in the scope of these changes. From this analysis, 27 positioning patterns ${ }^{5}$ were classified as "high intense" (clusters 3, 5 and 6), 37 as "medium intense" (clusters 2 and 4), whereas positioning paths from cluster n. 1 displayed a low intensity since values basically correspond to the average change of the sample. Finally, 13 of the 27 "high intense" positioning paths are displayed by Russell group's universities while the others are distributed across the other mission groups.

Compared to England, Italian positioning paths do not present high levels of intensity (Tab. 8). The only path that was classified as such is cluster n. 4, which consists of 3 HEIs, and might be considered as an outlier, while clusters n. 1, 2 concentrated their major changes only on two 
dimensions (EDUC_PROF and REG). Consequently, 12 positioning paths have been classified as "low intense", 43 "medium intense" and 3 "high intense".

\section{Table 7}

Table 8

\section{Discussion and conclusion}

Based on recent insights in the literature, the aim of this paper was to investigate how the analysis of the positioning of HEIs can increase our understanding of the diversity of HE systems. The methodological and exploratory nature of this article inevitably entails some limitations. First, the paper does not explain why HEIs change their positions longitudinally. We did not specifically consider the new reforms in the two countries such as the introduction of variable tuition fees in England or the NPM-based reform in Italy (Law n. 240/2010), which have altered the environmental conditions in which HEIs operate and could explained why HEIs position themselves in a way instead of others. This could be the object of study for a further study.

Second, this study investigated positioning paths as a given, without questioning if these are the result of either rational strategic choices or more passive adaptations towards exogenous forces. This dualistic dilemma can be a research topic itself, which cannot be investigated through this quantitative analysis.

Finally, the sample is not complete due to the lack of data for a group of HEIs of both HE systems. In particular, the absence of Italian private universities could have partially decreased the level of diversity of the HE system. These HEIs present a different governance regime that might provide them with more strategic opportunities to position uniquely. However, some studies illustrated that distinctiveness of Italian private HEIs can be found especially in the subject mix and less in the mission orientation (Rossi 2010; Cattaneo et al. 2018).

Despite these limitations, the empirical analysis is still relevant in showing how the analysis of positioning paths of HEIs can contribute to the study of diversity in HE, which is indeed the goal of this paper. In relation to this, three main contributions have been identified.

I. Clustering HEIs at different periods allowed identifying both convergence and differentiation processes within the same HE system, which are hidden by an analysis at the level of the entire HE system. In this respect, Table 2 illustrated that the English and Italian public HEIs are becoming more homogeneous in terms of research intensity (ISI) and increasingly heterogeneous in relation to their internationalization (INTERNAT). However, it cannot show, for example, whether the HEIs 
that are becoming more research-focused are also becoming more internationally oriented, or whether other combinations emerge.

The analysis of positioning paths (section 4.2) leads to a more comprehensive picture of diversity since it simultaneously considers all the indicators in which HEIs can either differentiate or converge (Daraio et al. 2011; Fumasoli and Huisman 2013). Positioning groups that result from the first clustering exercises (section 4.2) underline how convergence can occur along one indicator whereas distinctiveness can occur on a different indicator, which allows HEIs to balance both aspects as emerged from the previous works on mission statements (Mampaey et al. 2015; Seeber et al. 2017).

For instance, English clusters 1, 2 and 3 in 2014 (Tab. 6) are all teaching-oriented. However, they differ on their degree of regional orientation (cluster 1 vs 2) or a more 'generalist' vs 'specialized' subject mix (1 and 2 vs 3). Similarly, HEIs in clusters 4, 5 and 6 display convergence in their levels of research orientation but are quite dissimilar with respect to their international and third mission orientation.

These processes can be identified also in a less diversified HE system like the Italian, even if to a lower extent. Clusters 2 and 4 (Tab. 4) are indeed both more 'teaching oriented' but the former present values of third mission orientation that are even higher than the mean of the sample. Similarly, the other two clusters (1 and 3) are both more research-oriented but present a clear difference in their international orientation.

II. A longitudinal analysis of the positioning of HEIs contributes to understanding in which dimensions of the niche positioning shifts are more likely to occur, thus suggesting first of all the indicators that can be more meaningful in order to investigate diversity of HE systems over time (Fumasoli and Huisman 2013). Findings for both countries revealed indeed that HEIs are quite dissimilar in terms of their subject mix. However, distinctive changes within this indicator occurred rarely from 2004 to 2014 and were not significant in scale for both countries (Tab. 7 and 8). By contrast, indicators about the market size and the research orientation are those where positioning shifts occurred more radically.

Moreover, a longitudinal analysis of positioning revealed the actual processes (Ljungberg et al. 2009; Fumasoli and Huisman 2013) through which diversity of HE systems increase or decrease over time. For example, the decreasing levels of diversity of the English system in research (PHD, ISI) and third mission (THIRDM) (Table 2) seem to be the result of an increasing polarization between 'teaching vs research/third mission' orientation among HEIs from 2004 to 2014 as illustrated in section 4.2. Indeed, the split of cluster 2 in 2004 into either more research/third 
mission or teaching oriented clusters entails a decrease in the variety of HEIs since this cluster (2) represented something different from this polarization (a middle way between research and teaching) and led therefore to a lower level of diversity in the English HE system as reported in Table 2. Since diversity is also measured by the number of types (species) of HEIs (Huisman et al. 2007), it can be claimed that a type of HEI (Tab. 5, cluster 2) disappeared from 2004 to 2014 as a result of this polarization and consequently, the diversity of the system on these dimensions (PHD, ISI and THIRDM) decreased. The same mechanism can also be noticed in the Italian system and explains the decreasing value of diversity in the research intensity (ISI) (Tab. 2). Although this polarization is less evident, there is a more significant difference among clusters in the values of the ISI indicator from 2004 to 2014, as already illustrated in the findings section.

III. The analysis of positioning paths can contribute to identifying which groups of HEIs affect more the level of diversity. The findings highlighted that only 14 out of 95 English HEIs changed discontinuously their position (cluster) between 2004 and 2014. These distinctive shifts were the result of either a "medium" or a "high intense" paths (as identified by the second clustering exercise) and displayed by low-status and younger HEIs (post-1992 universities). Moreover, it also emerged that a discrete number of English HEIs (29), presented a "high" or medium" intense positioning path without changing clusters over time. These HEIs did not change their mix of activities/resources (horizontal diversity) but they improved their performances (vertical diversity) in one or more dimensions of the niche in which they were already located. Almost the totality of these HEIs belonged to either the Russell or the 1994 group, namely, higher-status institutions. By changing distinctively their position over time, low-status HEIs affect more the horizontal diversity of the HE system in two opposing directions. Some of these low-status HEIs tried to enhance their research orientation, imitating higher-status universities and contributing to decrease the diversity of the system. Others position themselves more distinctively since they strengthened their undergraduate-teaching focus but concurrently sharpened their either international or regional orientation.

Hence, it seems that 'positioning for prestige' through the imitation of higher-status institutions (Brewer et al. 2002; Toma 2012) and more distinctive behaviours from lower-status ones (Stensaker et al. 2018) both occurred within the English system. The more conservative and less deviant patterns of high-status universities contribute to keeping the diversity of HE system more stable despite an increasing competition (Carrasco and Brown 2013). Even if only preliminary, it can be argued that the analysis of positioning offers the opportunity to consider the impact of organizational variables, such as status, which can alter the expected relationship between 
competition and horizontal differentiation, confirming the literature on elite institutions (Van Vught 2008).

Finally, the methodological contribution of this paper can be further expanded in two future directions of research. First, the number and types of indicators can be extended by including environmental and other organizational variables. On the one hand, there are recent attempts to quantify environmental factors such as institutional autonomy and competition (Cattaneo et al. 2018). On the other hand, given that HEIs can display several heterogeneous positioning paths despite the same environmental conditions, organizational features and capabilities should be considered in order to explain this potential variety (Rossi 2009). Second, a quantitative analysis is not able to capture equally relevant aspects of positioning such as how the HEIs communicate its distinctiveness to external stakeholders and which model of HEI they aim to become. These elements could be viewed in documents such as mission statements and strategic plans of HEIs. A mix-method analysis of these texts and positioning indicators might contribute to increasing our understanding of positioning processes as interestingly illustrated in Seeber et al. (2017).

\section{Notes}

(1) Data of the affiliation of HEIs to national mission groups are available only for English HEIs since there is no such resource in Italy. The English mission groups considered are: Russell Group, 1994, University Alliance and Million +.

(2) Italian private universities and doctoral schools as well as English research institutes, conservatories, drama schools and Royal academies were excluded due to data availability problems.

(3) Diversity scores were computed for the two extremes of the considered time frame (2004 and 2014) and two intermediate years (2007 and 2010).

(4) For simplification purposes, all the distances in the dissimilarity matrix were summed, even though the resulting sum doubles distance values along the diagonal.

(5) Two of these 27 universities were affected by a merger between the university and an institute of research or a campus from another university. The merger improved the values of these two universities on some indicators, which has consequently enhanced the intensity of their positioning path.

\section{Acknowledgments}

The authors would like to thank the two anonymous referees, the participants at the XXXI Consortium of Higher Education Researchers (CHER) Annual Conference in Moscow as well as Dr. Andrea Riganti for his valuable and useful comments. Finally, we acknowledge the support by the Italian Ministry of Education, University, and Research through the PRIN 2015: "Comparing Governance Regime Changes in Higher Education". 


\section{References}

Birnbaum, R. 1983. Maintaining Diversity in Higher Education. San Francisco, USA: Jossey-Bass.

Bonaccorsi, A. 2009. "Division of Academic Labour is Limited by the Size of the Market. Strategy and Differentiation of European Universities in Doctoral Education." In Learning to Compete in European Universities: from Social Institution to Knowledge Business, edited by M. Holmén and M. McKelvey, 90-121. Cheltenham: Edward Elgar.

Bonaccorsi, A., and C. Daraio. 2007. Universities and Strategic Knowledge Creation. Cheltenham: Edward Elgar.

Bonaccorsi, A., and C. Daraio. 2008. "The Differentiation of the Strategic Profile of Higher Education Institutions: New Positioning Indicators based on Microdata." Scientometrics 74 (1): 1537. doi: 10.1007/s11192-008-0101-8.

Brankovic, J. 2018. "The Status Games they Play: Unpacking the Dynamics of Organisational Status Competition in Higher Education." Higher Education 75 (4): 695-709. doi: https://doi.org/10.1007/s10734-017-0169-2.

Brewer, D.J., S. M. Gates, and C. A. Goldman. 2002. In Pursuit of Prestige: Strategy and Competition in US Higher Education. New Brunswick: Transaction Press

Brown, R., and H. Carrasco. 2013. Everything for Sale? The Marketisation of UK Higher Education 1980-2012. London \& New York: Routledge.

Capano, G., M. Regini, and M. Turri. 2016. Changing Governance in Universities: Italian Higher Education in Comparative Perspective. New York: Palgrave-Macmillan.

Cattaneo, M., H. Horta, P. Malighetti, M. Meoli and S. Paleari. 2018. "The Relationship between Competition and programmatic Diversification." Studies in Higher Education (Article in press). doi: 10.1080/03075079.2018.1428947.

Codling, A. and V. L. Meek. 2006. "Twelve Propositions on Diversity in Higher Education." Higher Education Management and Policy 18 (3): 1-24. doi:https://doi.org/10.1787/17269822.

Daraio, C., A. Bonaccorsi, A. Geuna, B. Leporic, L. Bach, P. Bogetoft, M. F. Cardoso et al., 2011. "The European University Landscape: A micro Characterization based on Evidence from the Aquameth project.” Research Policy 40 (1): 148-164. doi:10.1016/j.respol.2010.10.009.

Deephouse, D. L. 1999. "To be Different, or to be the Same? It's a Question (and Theory) of Strategic Balance." Strategic Management Journal $20 \quad$ (2): 147-166. doi:https://doi.org/10.1002/(SICI)1097-0266(199902)20:2<147::AID-SMJ11>3.0.CO;2-Q

Frølich, N., J. Huisman, S. Slipersæter, B. Stensaker, and P. C. Pimentel Bòtas. 2013. “A Reinterpretation of Institutional Transformations in European Higher Education: Strategizing Pluralistic Organisations in Multiplex Environments." Higher Education 65 (1): 79-93. doi:10.1007/s10734-012-9582-8.

Fumasoli, T., and B. Lepori. 2011. "Patterns of Strategies in Swiss Higher Education." Higher Education 61 (2): 157-78. doi: 10.1007/s10734-010-9330-x. 
Fumasoli, T., and J. Huisman. 2013. "Strategic Agency and System Diversity: Conceptualizing Institutional Positioning in Higher Education." Minerva 51 (2): 155-69. doi: 10.1007/s11024-0139225-y.

Goedegebuure, L., A. Lysons, and V. L. Meek. 1993. "Diversity in Australian Higher Education?", Higher Education 25 (4): 395-410. doi:https://doi.org/10.1007/BF01383843.

Goglio, V., and M. Regini. 2017. "Processes and Stages of Differentiation in European Higher Education.” Higher Education Quarterly 71 (4): 320-337. doi:https://doi.org/10.1111/hequ.12133.

Huberty, C. J., E. M. Jordan, and W.C. Brandt. 2005. "Cluster Analysis in Higher Education Research". In Higher Education: Handbook of Theory and Research, edited by J. C. Smart, vol. 20, 437-457. Dordecht: Springer.

Huisman, J. 2000. "Higher Education Institutions: as Different as Chalk and Cheese?", Higher Education Policy 13 (1): 41-53. doi:10.1016/S0952-8733(99)00029-X.

Huisman, J., and J. Mampaey. 2018. "Use your Imagination: What UK Universities want you to Think of them." Oxford Review of Education 44 (4): 425-440. doi:10.1080/03054985.2017.1421154.

Huisman, J., V. L. Meek, and F. Wood. 2007. "Institutional Diversity in Higher Education: A Cross-national and Longitudinal Analysis." Higher Education Quarterly 61 (4): 563-577. doi:https://doi.org/10.1111/j.1468-2273.2007.00372.x.

Huisman, J., B. Lepori, M. Seeber, N. Frølich, and L. Scordato. 2015. "Measuring Institutional Diversity across Higher Education Systems." Research Evaluation 24 (4): 369-379. doi: 10.1093/reseval/rvv021.

Kraatz, M. S., and E. J. Zajac. 1996. "Exploring the Limits of the New institutionalism: Causes and Consequences of Illegitimate Organizational Change." American Sociological Review 61(5): 812836. doi:10.2307/2096455.

Sahlin, K., and L. Wedlin. 2008. "Circulating Ideas: Imitation, Translation and Editing." In The SAGE Handbook of Organizational Institutionalism edited by R. Greenwood, C. Oliver, K. Sahlin, and R. Suddaby, 218-242. London: Sage.

Ljungberg, D., M. Johansson, and M. McKelvey. 2009. "Polarization of the Swedish University Sector: Structural Characteristics and Positioning?" In Learning to Compete in European Universities: from Social Institution to Knowledge Business, edited by M. Holmén and M. McKelvey, 128-160. Cheltenham: Edward Elgar.

Maassen, P., and H. P. Potman. 1990. "Strategic Decision Making in Higher Education. An Analysis of the new Planning System in Dutch Higher Education." Higher Education 20 (4): 393 410. doi: 10.1007/BF00136220.

Mampaey, J., J. Huisman, and M. Seeber. 2015. "Branding of Flemish Higher Education Institutions: A Strategic Balance Perspective.” Higher Education Research \& Development 34 (6): 1178-1191. doi:10.1080/07294360.2015.1024634.

Morphew, C. C. 2009. "Conceptualizing Change in the Institutional Diversity of US Colleges and Universities." The Journal of Higher Education $80 \quad$ (3) 243-269. doi:10.1080/00221546.2009.11779012. 
Morphew, C. C., T. Fumasoli, and B. Stensaker. 2018. "Changing Missions? How the Strategic Plans of Research-intensive Universities in Northern Europe and North America Balance Competing Identities." Studies in Higher Education 43 (6): 1074-1088. doi:10.1080/03075079.2016.1214697.

Neave, G. 1979. “Academic Drift: Some Views from Europe.” Studies in Higher Education 4 (2): 143-159. doi:10.1080/03075077912331376927.

Oliver, C. 1991. "Strategic Responses to Institutional Processes." The Academy of Management Review, 16 (1): 145-179. doi:10.2307/258610.

Paradeise, C., and J. C. Thoenig. 2013. "Academic Institutions in Search of Quality: Local Orders and Global Standards.” Organization Studies 34 (2): 189-218. doi:10.1177/0170840612473550.

Pedersen, J. S., and F. Dobbin. 2006. "In Search of Identity and Legitimation: Bridging Organizational Culture and Neo-institutionalism." American Behavioral Scientist 49 (7): 897-907. doi:10.1177/0002764205284798.

Porter, M. E. 1985. Competitive Advantage: Creating and Sustaining Superior Performance. New York: Free Press.

Riesman, D. 1956. Constraint and Variety in American Education. Lincoln: University of Nebraska Press.

Rossi, F. 2009. 'Universities' Access to Research Funds: Do Institutional Features and Strategies Matter?." Tertiary Education and Management 15 (2): 113-135. doi:10.1080/13583880902869596.

Rossi, F. 2010. "Massification, Competition and Organizational Diversity in Higher Education: Evidence from Italy." Studies in Higher Education 35 (3): 277-300. doi:10.1080/03075070903050539.

Seeber, M., V. Barberio, J. Huisman, and J. Mampaey. 2017. "Factors Affecting the Content of Universities' Missions Statements: An Analysis of the United Kingdom Higher Education System." Studies in Higher Education (Article in Press). doi:10.1080/03075079.2017.1349743.

Silander, C., and U. Haake. 2016. "Gold-diggers, Supporters and Inclusive Profilers: Strategies for Profiling Research in Swedish Higher Education." Studies in Higher Education 42 (11): 2009-2025. doi:10.1080/03075079.2015.1130031.

Stensaker, B., J. J. Lee, G. Rhoades, S. Ghosh, S. Castiello-Gutiérrez, H. Vance, A. Çalıkoğlu, V. Kramer, S. Liu, M. Sayed Marei, L. O'Toole, I. Pavlyutkin, and C. Peel. 2018. "Stratified University Strategies: The Shaping of Institutional Legitimacy in a Global Perspective." The Journal of Higher Education (Article in Press). doi:https://doi.org/10.1080/00221546.2018.1513306.

Suchman, M. C. 1995. "Managing Legitimacy: Strategic and Institutional Approaches.” Academy of Management Review 20 (3): 571-610. doi:10.2307/258788.

Toma, J. D. 2012. "Institutional Strategy. Positioning for Prestige." In The Organization of Higher Education: Managing Colleges for a new Era. Baltimore, edited by M. N. Bastedo, 118-159. Baltimore: Jonhs-Hopkins University Press.

Van Vught, F. 2008. "Mission Diversity and Reputation in Higher Education." Higher Education Policy 21 (2): 151-174. doi:10.1057/hep.2008.5. 
Wang, C. and Q. Zha. 2018. "Measuring systemic Diversity of Chinese Universities: a Clusteringmethod pproach." Quality and Quantity 52 (3): 1331-1347. doi:10.1007/s11135-017-0524-5. 
Table 1. Indicators used in the empirical analyses

\begin{tabular}{|c|l|l|l|}
\hline Dimension of the niche & \multicolumn{1}{|c|}{ Indicator } & \multicolumn{1}{|c|}{ Definition } & \multicolumn{1}{|c|}{ Code } \\
\hline \multirow{3}{*}{ Core functions of HEIs } & $\begin{array}{l}\text { Educational profile } \\
\text { involvement) }\end{array}$ & $\begin{array}{l}\text { Share of undergraduate students } \\
\text { as a share of the total }\end{array}$ & EDUC_PROF \\
\cline { 2 - 4 } & Research intensity & $\begin{array}{l}\text { Number of Web of Science } \\
\text { publications per academics } \\
\text { of the total }\end{array}$ & ISI \\
\cline { 2 - 5 } & Third mission & $\begin{array}{l}\text { Third party revenue as a share of } \\
\text { total income }\end{array}$ & THIRDM \\
\hline \multirow{2}{*}{ Subject mix of HEIs } & Subject mix & $\begin{array}{l}\text { Distribution of students by } \\
\text { discipline }\end{array}$ & SUBMIX \\
\hline \multirow{2}{*}{ Structural features } & Size & $\begin{array}{l}\text { Share of international students as } \\
\text { a share of the total* }\end{array}$ & INTERNAT \\
\cline { 2 - 5 } & Regional orientation & $\begin{array}{l}\text { Share of new students that are } \\
\text { resident in the same region of } \\
\text { the university as a share of the } \\
\text { total }\end{array}$ & REG \\
\hline
\end{tabular}

*Values of PHD and INTERNAT are multiplied by 1000

Table 2. Mean sum of Euclidean squared distance (MSSD) for each indicator and country in 2004, 2007, 2010 and 2014

\begin{tabular}{|c|c|c|c|c|c|c|c|c|}
\hline \multicolumn{9}{|c|}{ ENGLAND (n=95) } \\
\hline Indicator/year & EDUC_PROF & PHD & ISI & THIRDM & INTERNAT & REG & SUBMIX & SIZE \\
\hline 2004 & 0.052 & 2.715 & 1.611 & 1.105 & 0.776 & 0.360 & 0.474 & 0.533 \\
\hline 2007 & 0.051 & 2.636 & 1.299 & 1.340 & 0.865 & 0.306 & 0.499 & 0.476 \\
\hline 2010 & 0.058 & 2.423 & 1.341 & 1.640 & 0.774 & 0.482 & 0.433 & 0.450 \\
\hline 2014 & 0.056 & 1.658 & 1.087 & 0.856 & 0.894 & 0.430 & 0.382 & 0.465 \\
\hline \multicolumn{9}{|c|}{ ITALY (n=58) } \\
\hline Indicator/year & EDUC_PROF & PHD & ISI & THIRDM & INTERNAT & REG & SUBMIX & SIZE \\
\hline 2004 & 0.032 & 0.282 & 0.237 & 1.276 & 3.006 & 0.087 & 0.512 & 1.831 \\
\hline 2007 & 0.028 & 0.264 & 0.234 & 1.834 & 3.701 & 0.086 & 0.500 & 1.501 \\
\hline 2010 & 0.035 & 0.353 & 0.197 & 1.739 & 4.412 & 0.081 & 0.497 & 1.416 \\
\hline 2014 & 0.047 & 0.406 & 0.179 & 1.189 & 5.509 & 0.151 & 0.500 & 1.400 \\
\hline
\end{tabular}


Table 3. Positioning indicators for each Italian cluster* in 2004

\begin{tabular}{|c|c|c|c|c|c|c|c|c|}
\hline Cluster & EDUC_PROF & PHD & ISI & THIRDM & INTERNAT & REG & SUBMIX & TYPE OF POSITIONING \\
\hline $1(n=22)$ & $\begin{array}{l}0.617 \\
(0.059)\end{array}$ & $\begin{array}{l}8.014 \\
(2.441)\end{array}$ & $\begin{array}{l}0.984 \\
(0.190)\end{array}$ & $\begin{array}{l}0.085 \\
(0.044)\end{array}$ & $\begin{array}{l}7.031 \\
(7.389)\end{array}$ & $\begin{array}{l}0.755 \\
(0.154)\end{array}$ & $\begin{array}{l}0.549 \\
(0.147)\end{array}$ & $\begin{array}{l}\text { Highest research and third mission orientation }+ \\
\text { highest international and regional orientation } \\
\text { (generalist subject mix) }\end{array}$ \\
\hline $2(n=11)$ & $\begin{array}{l}0.581 \\
(0.042)\end{array}$ & $\begin{array}{c}6.225 \\
(0.906)\end{array}$ & $\begin{array}{l}0.695 \\
(0.139)\end{array}$ & $\begin{array}{l}0.029 \\
(0.015)\end{array}$ & $\begin{array}{l}1.260 \\
(1.239)\end{array}$ & $\begin{array}{l}0.939 \\
(0.072)\end{array}$ & $\begin{array}{l}0.557 \\
(0.075)\end{array}$ & $\begin{array}{l}\text { Average teaching and research orientation }+ \\
\text { highest regional orientation (generalist) }\end{array}$ \\
\hline $3(n=25)$ & $\begin{array}{l}0.647 \\
(0.078)\end{array}$ & $\begin{array}{l}5.174 \\
(2.111)\end{array}$ & $\begin{array}{l}0.700 \\
(0.332)\end{array}$ & $\begin{array}{l}0.033 \\
(0.025)\end{array}$ & $\begin{array}{r}4.904 \\
(5.990)\end{array}$ & $\begin{array}{l}0.815 \\
(0.136)\end{array}$ & $\begin{array}{l}0.292 \\
(0.192)\end{array}$ & $\begin{array}{l}\text { Average teaching and research orientation + } \\
\text { average international and regional orientation } \\
\text { (specialized subject mix) }\end{array}$ \\
\hline $\begin{array}{c}\text { mean value of } \\
\text { the sample }\end{array}$ & $\begin{array}{c}0.623 \\
(0.069)\end{array}$ & $\begin{array}{l}\mathbf{0 . 6 4 6} \\
(2.425)\end{array}$ & $\begin{array}{l}0.803 \\
(0.285)\end{array}$ & $\begin{array}{c}0.052 \\
(0.041)\end{array}$ & $\begin{array}{l}0.502 \\
(6.308)\end{array}$ & $\begin{array}{c}0.804 \\
(0.152)\end{array}$ & $\begin{array}{l}0.440 \\
(0.203)\end{array}$ & \\
\hline
\end{tabular}

*For each cluster the mean and standard deviation (italics) are reported

Table 4. Positioning indicators for each Italian cluster* in 2014

\begin{tabular}{|c|c|c|c|c|c|c|c|c|}
\hline Cluster & EDUC_PROF & PHD & ISI & THIRDM & INTERNAT & REG & SUBMIX & TYPE OF POSITIONING \\
\hline $1(\mathrm{n}=19)$ & $\begin{array}{c}0.609 \\
(0.054)\end{array}$ & $\begin{array}{c}6.447 \\
(1.908)\end{array}$ & $\begin{array}{c}2.228 \\
(0.305)\end{array}$ & $\begin{array}{c}0.066 \\
(0.027)\end{array}$ & $\begin{array}{c}15.317 \\
(13.21)\end{array}$ & $\begin{array}{c}0.741 \\
(0.111)\end{array}$ & $\begin{array}{l}0.620 \\
(0.099)\end{array}$ & $\begin{array}{l}\text { Highest research and high third mission orientation } \\
\text { + high international and regional orientation } \\
\text { (generalist subject mix) }\end{array}$ \\
\hline $2(\mathrm{n}=9)$ & $\begin{array}{c}0.659 \\
(0.062)\end{array}$ & $\begin{array}{c}4.364 \\
(1.098)\end{array}$ & $\begin{array}{c}1.498 \\
(0.450)\end{array}$ & $\begin{array}{c}0.149 \\
(0.036)\end{array}$ & $\begin{array}{c}5.727 \\
(4.64)\end{array}$ & $\begin{array}{c}0.866 \\
(0.120)\end{array}$ & $\begin{array}{c}0.501 \\
(0.221)\end{array}$ & $\begin{array}{l}\text { Average teaching and research + highest third } \\
\text { mission orientation + highest regional orientation } \\
\text { (generalist) }\end{array}$ \\
\hline $3(\mathrm{n}=11)$ & $\begin{array}{c}0.557 \\
(0.079)\end{array}$ & $\begin{array}{c}6.825 \\
(3.194)\end{array}$ & $\begin{array}{c}1.812 \\
(0.689)\end{array}$ & $\begin{array}{c}0.0782 \\
(0.037)\end{array}$ & $\begin{array}{c}27.048 \\
(32.91)\end{array}$ & $\begin{array}{c}0.752 \\
(0.190)\end{array}$ & $\begin{array}{c}0.205 \\
(0.186)\end{array}$ & $\begin{array}{l}\text { More research oriented + highest international and } \\
\text { regional orientation (specialized subject mix) }\end{array}$ \\
\hline $4(\mathrm{n}=19)$ & $\begin{array}{c}0.637 \\
(0.087)\end{array}$ & $\begin{array}{c}3.603 \\
(1.368)\end{array}$ & $\begin{array}{c}1.389 \\
(0.313)\end{array}$ & $\begin{array}{c}0.020 \\
(0.021)\end{array}$ & $\begin{array}{c}5.250 \\
(10.09)\end{array}$ & $\begin{array}{c}0.834 \\
(0.175)\end{array}$ & $\begin{array}{c}0.508 \\
(0.175)\end{array}$ & $\begin{array}{l}\text { More teaching orientation + high regional } \\
\text { orientation (generalist) }\end{array}$ \\
\hline $\begin{array}{c}\text { mean value } \\
\text { of the } \\
\text { sample }\end{array}$ & $\begin{array}{c}\mathbf{0 . 6 1 6} \\
(\mathbf{0 . 0 7 8})\end{array}$ & $\begin{array}{c}\mathbf{5 . 2 6 4} \\
\mathbf{( 2 . 3 8 4})\end{array}$ & $\begin{array}{c}\mathbf{1 . 7 6 1} \\
(\mathbf{0 . 5 4 9})\end{array}$ & $\begin{array}{c}\mathbf{0 . 0 6 6} \\
(\mathbf{0 . 0 5 1})\end{array}$ & $\begin{array}{c}\mathbf{1 2 . 7 5 6} \\
(\mathbf{1 8 . 6 7})\end{array}$ & $\begin{array}{c}\mathbf{0 . 7 9 3} \\
(\mathbf{0 . 1 5 7})\end{array}$ & $\begin{array}{c}\mathbf{0 . 4 8 6} \\
(\mathbf{0 . 2 1 7})\end{array}$ & \\
\hline
\end{tabular}

*For each cluster the mean and standard deviation (italics) are reported 
Table 5. Positioning indicators for each English cluster* in 2004

\begin{tabular}{|c|c|c|c|c|c|c|c|c|}
\hline Cluster & EDUC_PROF & PHD & ISI & THIRDM & INTERNAT & REG & SUBMIX & TYPE OF POSITIONING \\
\hline $1(n=27)$ & $\begin{array}{c}0.833 \\
(0.044)\end{array}$ & $\begin{array}{l}11.84 \\
(4.872)\end{array}$ & $\begin{array}{c}0.204 \\
(0.131)\end{array}$ & $\begin{array}{c}0.094 \\
(0.043)\end{array}$ & $\begin{array}{l}99.53 \\
(36.14)\end{array}$ & $\begin{array}{c}0.349 \\
(0.087)\end{array}$ & $\begin{array}{c}0.486 \\
(0.119)\end{array}$ & $\begin{array}{l}\text { Undergraduate teaching oriented }+ \text { national } \\
\text { market size (generalist subject mix) }\end{array}$ \\
\hline $2(n=21)$ & $\begin{array}{c}0.750 \\
(0.065)\end{array}$ & $\begin{array}{l}17.42 \\
(12.10)\end{array}$ & $\begin{array}{c}0.509 \\
(0.418)\end{array}$ & $\begin{array}{c}0.125 \\
(0.067)\end{array}$ & $\begin{array}{l}193.09 \\
(49.94)\end{array}$ & $\begin{array}{c}0.415 \\
(0.131)\end{array}$ & $\begin{array}{c}0.534 \\
(0.183)\end{array}$ & $\begin{array}{l}\text { Both average teaching, research and third } \\
\text { mission oriented + }+ \text { high international } \\
\text { orientation (generalist) }\end{array}$ \\
\hline $3(n=15)$ & $\begin{array}{c}0.816 \\
(0.090)\end{array}$ & $\begin{array}{l}6.93 \\
(6.451)\end{array}$ & $\begin{array}{c}0.135 \\
(0.205)\end{array}$ & $\begin{array}{c}0.079 \\
(0.076)\end{array}$ & $\begin{array}{l}58.14 \\
(35.48)\end{array}$ & $\begin{array}{c}0.434 \\
(0.152)\end{array}$ & $\begin{array}{c}0.119 \\
(0.069)\end{array}$ & $\begin{array}{l}\text { Undergraduate teaching oriented (specialized } \\
\text { subject mix) }\end{array}$ \\
\hline $4(n=30)$ & $\begin{array}{c}0.693 \\
(0.053)\end{array}$ & $\begin{array}{l}61.51 \\
(30.57)\end{array}$ & $\begin{array}{l}1.473 \\
(0.734)\end{array}$ & $\begin{array}{c}0.287 \\
(0.108)\end{array}$ & $\begin{array}{c}197 \\
(62.58)\end{array}$ & $\begin{array}{c}0.209 \\
(0.101)\end{array}$ & $\begin{array}{c}0.461 \\
(0.141)\end{array}$ & $\begin{array}{l}\text { Highest research and third mission orientation } \\
+ \text { high international and national orientation } \\
\text { (generalist) }\end{array}$ \\
\hline $5(\mathrm{n}=2)$ & $\begin{array}{c}0.382 \\
(0.087)\end{array}$ & $\begin{array}{l}132.28 \\
(50.28)\end{array}$ & $\begin{array}{c}0.866 \\
(0.176)\end{array}$ & $\begin{array}{c}0.135 \\
(0.018)\end{array}$ & $\begin{array}{c}477 \\
(198.53)\end{array}$ & $\begin{array}{c}0.230 \\
(0.030)\end{array}$ & $\begin{array}{c}0.157 \\
(0.210)\end{array}$ & $\begin{array}{l}\text { Research oriented and postgraduate teaching + } \\
\text { highest international and national orientation } \\
\text { (specialized) }\end{array}$ \\
\hline $\begin{array}{l}\text { mean value of the } \\
\text { sample }\end{array}$ & $\begin{array}{c}0.762 \\
(0.100)\end{array}$ & $\begin{array}{c}29.43 \\
(32.90)\end{array}$ & $\begin{array}{c}0.645 \\
(0.717)\end{array}$ & $\begin{array}{c}0.156 \\
(0.115)\end{array}$ & $\begin{array}{c}149 \\
(90.21)\end{array}$ & $\begin{array}{c}0.333 \\
(0.142)\end{array}$ & $\begin{array}{c}0.424 \\
(0.196)\end{array}$ & \\
\hline
\end{tabular}

*For each cluster the mean and standard deviation (italics) are reported 
Table 6. Positioning indicators for each English cluster* in 2014

\begin{tabular}{|c|c|c|c|c|c|c|c|c|}
\hline Cluster & EDUC_PROF & PHD & ISI & THIRDM & INTERNAT & REG & SUBMIX & TYPE OF POSITIONING \\
\hline $1(n=23)$ & $\begin{array}{c}0.823 \\
(0.043)\end{array}$ & $\begin{array}{l}20.05 \\
(7.62)\end{array}$ & $\begin{array}{c}0.384 \\
(0.210)\end{array}$ & $\begin{array}{c}0.065 \\
(0.036)\end{array}$ & $\begin{array}{c}125.9 \\
(43.06)\end{array}$ & $\begin{array}{c}0.333 \\
(0.068)\end{array}$ & $\begin{array}{c}0.444 \\
(0.090)\end{array}$ & $\begin{array}{l}\text { Undergraduate teaching oriented + national } \\
\text { orientation (generalist subject mix) }\end{array}$ \\
\hline $2(n=17)$ & $\begin{array}{l}0.808 \\
(0.041)\end{array}$ & $\begin{array}{c}24.78 \\
(14.13)\end{array}$ & $\begin{array}{c}0.483 \\
(0.228)\end{array}$ & $\begin{array}{c}0.064 \\
(0.032)\end{array}$ & $\begin{array}{l}163.5 \\
(87.84)\end{array}$ & $\begin{array}{c}0.527 \\
(0.092)\end{array}$ & $\begin{array}{c}0.514 \\
(0.073)\end{array}$ & $\begin{array}{l}\text { Undergraduate teaching oriented }+ \text { more regional } \\
\text { orientation (generalist) }\end{array}$ \\
\hline $3(n=18)$ & $\begin{array}{c}0.784 \\
(0.068)\end{array}$ & $\begin{array}{l}20.97 \\
(20.18)\end{array}$ & $\begin{array}{c}0.283 \\
(0.236)\end{array}$ & $\begin{array}{c}0.061 \\
(0.055)\end{array}$ & $\begin{array}{l}73.57 \\
(64.89)\end{array}$ & $\begin{array}{c}0.467 \\
(0.153)\end{array}$ & $\begin{array}{c}0.205 \\
(0.157)\end{array}$ & $\begin{array}{l}\text { Undergraduate teaching oriented (specialized } \\
\text { subject mix) }\end{array}$ \\
\hline $4(n=30)$ & $\begin{array}{c}0.701 \\
(0.055)\end{array}$ & $\begin{array}{l}76.60 \\
(23.04)\end{array}$ & $\begin{array}{l}1.717 \\
(0.708)\end{array}$ & $\begin{array}{c}0.216 \\
(0.088)\end{array}$ & $\begin{array}{c}264.2 \\
(58.38)\end{array}$ & $\begin{array}{c}0.212 \\
(0.102)\end{array}$ & $\begin{array}{c}0.526 \\
(0.138)\end{array}$ & $\begin{array}{l}\text { Research and third mission orientation }+ \text { high } \\
\text { international and national orientation (generalist) }\end{array}$ \\
\hline $5(n=4)$ & $\begin{array}{c}0.569 \\
(0.077)\end{array}$ & $\begin{array}{l}212.3 \\
(49.95)\end{array}$ & $\begin{array}{l}2.357 \\
(0.294)\end{array}$ & $\begin{array}{c}0.519 \\
(0.120)\end{array}$ & $\begin{array}{c}367.1 \\
(84.98)\end{array}$ & $\begin{array}{c}0.155 \\
(0.057)\end{array}$ & $\begin{array}{c}0.618 \\
(0.152)\end{array}$ & $\begin{array}{l}\text { Highest research oriented (postgraduate teaching) } \\
\text { and highest third mission. + high international and } \\
\text { national orientation (generalist) }\end{array}$ \\
\hline $6(n=3)$ & $\begin{array}{c}0.432 \\
(0.090)\end{array}$ & $\begin{array}{l}84.73 \\
(73.28)\end{array}$ & $\begin{array}{l}1.211 \\
(0.246)\end{array}$ & $\begin{array}{c}0.109 \\
(0.077)\end{array}$ & $\begin{array}{l}462.1 \\
(179.4)\end{array}$ & $\begin{array}{c}0.293 \\
(0.161)\end{array}$ & $\begin{array}{l}0.235 \\
(0.207)\end{array}$ & $\begin{array}{l}\text { Research orientation (postgraduate teaching) + } \\
\text { highest international and national orientation } \\
\text { (specialized) }\end{array}$ \\
\hline $\begin{array}{c}\text { mean value of the } \\
\text { sample }\end{array}$ & $\begin{array}{c}0.758 \\
(0.099)\end{array}$ & $\begin{array}{c}49.07 \\
(48.58)\end{array}$ & $\begin{array}{c}0.913 \\
(0.814)\end{array}$ & $\begin{array}{c}0.132 \\
(0.124)\end{array}$ & $\begin{array}{c}187.2 \\
(116.8)\end{array}$ & $\begin{array}{c}0.344 \\
(0.161)\end{array}$ & $\begin{array}{c}0.438 \\
(0.177)\end{array}$ & \\
\hline
\end{tabular}

*For each cluster the mean and standard deviation (italics) are reported 
Table 7. Difference between 2004 and 2014 for each English cluster*

\begin{tabular}{|c|c|c|c|c|c|c|c|c|}
\hline Cluster & EDUC_PROF & PHD & ISI & THIRDM & INTERNAT & REG & SUBMIX & $\begin{array}{c}\text { INTESITY OF POSITIONING } \\
\text { PATH }\end{array}$ \\
\hline $1(\mathrm{n}=31)$ & $\begin{array}{c}-0.009 \\
(0.0432)\end{array}$ & $\begin{array}{l}-9.818 \\
(11.35)\end{array}$ & $\begin{array}{l}-0.143 \\
(0.096)\end{array}$ & $\begin{array}{c}0.013 \\
(0.033)\end{array}$ & $\begin{array}{l}-28.50 \\
(43.29)\end{array}$ & $\begin{array}{c}0.001 \\
(0.050)\end{array}$ & $\begin{array}{l}-0.003 \\
(0.058)\end{array}$ & $\begin{array}{l}\text { Low: values close to the mean } \\
\text { difference }\end{array}$ \\
\hline $2(\mathrm{n}=29)$ & $\underline{0.037}^{* *}$ & $\begin{array}{l}-7.821 \\
(16.15)\end{array}$ & $\begin{array}{c}0.058 \\
(0.142)\end{array}$ & $\begin{array}{c}0.005 \\
(0.045)\end{array}$ & $\frac{-40.05}{(44.01)}$ & $\frac{0.026}{(0.065)}$ & $\begin{array}{l}-0.007 \\
(0.060)\end{array}$ & $\begin{array}{l}\text { Medium: Increase in undergraduate } \\
\text { and regional orientation }\end{array}$ \\
\hline $3(n=7)$ & $\frac{-0.071}{(0.080)}$ & $\begin{array}{l}-7.480 \\
(15.41)\end{array}$ & $\begin{array}{l}-0.117 \\
(0.178)\end{array}$ & $\begin{array}{l}-0.102 \\
(0.029)\end{array}$ & $\begin{array}{c}12.90 \\
(66.99)\end{array}$ & $\frac{0.074}{(0.050)}$ & $\begin{array}{c}0.066 \\
(0.091)\end{array}$ & $\begin{array}{l}\text { High: Increase in postgraduate } \\
\text { teaching and regional orientation }\end{array}$ \\
\hline $4(n=8)$ & $\begin{array}{l}-0.013 \\
(0.037)\end{array}$ & $\begin{array}{c}5.539 \\
(22.55)\end{array}$ & $\begin{array}{l}-0.028 \\
(0.228)\end{array}$ & $\begin{array}{l}-0.004 \\
(0.031)\end{array}$ & $\frac{69.11}{(68.85)}$ & $\begin{array}{c}0.004 \\
(0.047)\end{array}$ & $\frac{-0.175}{(0.087)}$ & $\begin{array}{l}\text { Medium: Increase in international } \\
\text { orientation and a subject mix more } \\
\text { specialized }\end{array}$ \\
\hline $5(\mathrm{n}=15)$ & $\begin{array}{c}0.013 \\
(0.061)\end{array}$ & $\begin{array}{c}5.455 \\
(17.92)\end{array}$ & $\frac{0.231}{(0.195)}$ & $\begin{array}{c}0.000 \\
(0.034)\end{array}$ & $\frac{65.82}{(30.20)}$ & $\frac{-0.062}{(0.065)}$ & $\begin{array}{c}0.052 \\
(0.090)\end{array}$ & $\begin{array}{l}\text { High: Increase in research (ISI), } \\
\text { international and national orientation }\end{array}$ \\
\hline $6(n=5)$ & $\frac{-0.067}{(0.041)}$ & $\frac{91.48}{(33.99)}$ & $\begin{array}{c}0.124 \\
(0.173)\end{array}$ & $\frac{0.035}{(0.088)}$ & $\frac{82.93}{(43.20)}$ & $\frac{-0.081}{(0.061)}$ & $\frac{0.091}{(0.073)}$ & $\begin{array}{l}\text { High: Increase in research } \\
\text { (postgraduate }+\mathrm{PhD} \text { ratio), third } \\
\text { mission, international and national } \\
\text { orientation }\end{array}$ \\
\hline $\begin{array}{c}\text { mean } \\
\text { difference } \\
2004-2014 \text { of } \\
\text { the sample }\end{array}$ & $\begin{array}{c}-0.010 \\
(0.061)\end{array}$ & $\begin{array}{l}19.640 \\
(27.86)\end{array}$ & $\begin{array}{c}0.267 \\
(0.196)\end{array}$ & $\begin{array}{l}-0.023 \\
(0.049)\end{array}$ & $\begin{array}{c}37.81 \\
(65.33)\end{array}$ & $\begin{array}{c}0.011 \\
(0.069)\end{array}$ & $\begin{array}{c}0.020 \\
(0.092)\end{array}$ & \\
\hline
\end{tabular}

*For each cluster the mean and standard deviation (italics) are reported

** Values 1 or more times higher/lower than the mean difference of the sample are underlined 
Table 8. Difference between 2004 and 2014 for each Italian cluster*

\begin{tabular}{|c|c|c|c|c|c|c|c|c|}
\hline Cluster & EDUC_PROF & PHD & ISI & THIRDM & INTERNAT & REG & SUBMIX & $\begin{array}{c}\text { INTESITY OF } \\
\text { POSITIONING PATH }\end{array}$ \\
\hline $1(\mathrm{n}=30)$ & $\frac{0.036}{(0.051)}^{* *}$ & $\begin{array}{c}0,85 \\
(2,816)\end{array}$ & $\begin{array}{l}-0.055 \\
(0.313)\end{array}$ & $\begin{array}{c}0.006 \\
(0.045)\end{array}$ & $\begin{array}{c}-1,30 \\
(10.330)\end{array}$ & $\frac{0.016}{(0.073)}$ & $\begin{array}{c}0.031 \\
(0.072)\end{array}$ & $\begin{array}{l}\text { Medium: Increase in } \\
\text { undergraduate and regional } \\
\text { orientation }\end{array}$ \\
\hline $2(n=13)$ & $\frac{-0.065}{(0.057)}$ & $\frac{-1,68}{(2.736)}$ & $\begin{array}{l}-0.170 \\
(0.234)\end{array}$ & $\begin{array}{l}-0.017 \\
(0.027)\end{array}$ & $\begin{array}{l}-4,45 \\
(3.716)\end{array}$ & $\frac{0.012}{(0.035)}$ & $\begin{array}{l}-0.002 \\
(0.034)\end{array}$ & $\begin{array}{llr}\text { Medium: } & \text { Increase in } \\
\text { postgraduate } & \text { and regional } \\
\text { orientation } & & \\
\end{array}$ \\
\hline $3(\mathrm{n}=12)$ & $\begin{array}{l}-0.016 \\
(0.040)\end{array}$ & $\begin{array}{c}0,29 \\
(1,735)\end{array}$ & $\begin{array}{c}0.342 \\
(0.254)\end{array}$ & $\begin{array}{l}-0.002 \\
(0.023)\end{array}$ & $\begin{array}{l}-3,70 \\
(2.828)\end{array}$ & $\frac{-0.017}{(0.035)}$ & $\begin{array}{l}-0.058 \\
(0.050)\end{array}$ & $\begin{array}{l}\text { Low: differences close to the } \\
\text { mean of the sample }\end{array}$ \\
\hline $4(n=3)$ & $\frac{-0.020}{(0.080)}$ & $\frac{2,53}{(1,878)}$ & $\begin{array}{c}0.535 \\
(0.076)\end{array}$ & $\frac{0.026}{(0.032)}$ & $\frac{47,04}{(36.803)}$ & $\frac{-0.190}{(0.068)}$ & $\begin{array}{l}-0.028 \\
(0.028)\end{array}$ & $\begin{array}{l}\text { High: Increase in } \mathrm{PhD} \text { ratio, } \\
\text { third mission, international } \\
\text { and national orientation }\end{array}$ \\
\hline $\begin{array}{l}\text { mean difference 2004- } \\
2014 \text { of the sample }\end{array}$ & $\begin{array}{l}-0.009 \\
(0.065)\end{array}$ & $\begin{array}{c}-1.19 \\
(2.762)\end{array}$ & $\begin{array}{c}0.734 \\
(0.348)\end{array}$ & $\begin{array}{c}0.014 \\
(0.038)\end{array}$ & $\begin{array}{c}7,73 \\
(15,195)\end{array}$ & $\begin{array}{l}-0.010 \\
(0.073)\end{array}$ & $\begin{array}{c}0.046 \\
(0.068)\end{array}$ & \\
\hline
\end{tabular}

*For each cluster the mean and standard deviation (italics) are reported

** Values 1 or more times higher/lower than the mean difference of the sample are underlined 


\section{Appendix}

Table 1. data sources and formula of the indicators

\begin{tabular}{|c|c|c|c|}
\hline Indicator & Formula & Source of Italian data & $\begin{array}{l}\text { Source of English } \\
\text { data }\end{array}$ \\
\hline EDUC-PROF & $\begin{array}{l}\text { n. of ISCED } 6^{1} \text { students / ISCED } 6 \\
+7\end{array}$ & $\begin{array}{l}\text { administrative data from the } \\
\text { Ministry of Education, } \\
\text { University and Research } \\
\text { (MIUR) website }\end{array}$ & $\begin{array}{l}\text { data from the Higher } \\
\text { Education Statistical } \\
\text { Agency (HESA) website }\end{array}$ \\
\hline PHD & ISCED 8 / ISCED 6+7+8 & $\begin{array}{l}\text { administrative data from the } \\
\text { MIUR, available upon } \\
\text { permission }\end{array}$ & $\begin{array}{l}\text { data from the HESA } \\
\text { website }\end{array}$ \\
\hline ISI & $\begin{array}{l}\begin{array}{l}\text { ISI publications / n. of FTE } \\
\text { academics }\end{array} \\
\end{array}$ & InCites database & InCites database \\
\hline THIRDM & Third party funding / total income & $\begin{array}{l}\text { administrative data from the } \\
\text { MIUR available upon } \\
\text { permission }\end{array}$ & $\begin{array}{l}\text { data from the HESA } \\
\text { website }\end{array}$ \\
\hline SUBMIX & $\begin{array}{l}\text { Normalized Herfindahl index on the } \\
\text { number of students ISCED } 6+7 \text { by each } \\
\text { of the } 11 \text { fields of study }{ }^{2}\end{array}$ & $\begin{array}{l}\text { administrative data from the } \\
\text { MIUR website }\end{array}$ & $\begin{array}{l}\text { data from the HESA } \\
\text { website }\end{array}$ \\
\hline INTERNAT & $\begin{array}{l}\text { International }^{3} \text { ISCED } 6+7 / \text { total } \\
\text { ISCED } 6+7\end{array}$ & $\begin{array}{l}\text { administrative data from the } \\
\text { MIUR website }\end{array}$ & $\begin{array}{l}\text { data from the HESA } \\
\text { website }\end{array}$ \\
\hline REG & $\begin{array}{l}\text { New ISCED } 6 \text { students/unique } \\
\text { applicants }{ }^{4} \text { resident in the same region } \\
\text { of the university / total n. of new } \\
\text { ISCED } 6 \text { students/unique applicants }\end{array}$ & $\begin{array}{l}\text { administrative data from the } \\
\text { MIUR website }\end{array}$ & $\begin{array}{l}\text { Not-public data about } \\
\text { number of applicants and } \\
\text { unique applicants from } \\
\text { UCAS website }\end{array}$ \\
\hline SIZE & Students ISCED $6+7+8$ & $\begin{array}{l}\text { administrative data from the } \\
\text { MIUR website }\end{array}$ & $\begin{array}{l}\text { data from the HESA } \\
\text { website }\end{array}$ \\
\hline
\end{tabular}

\section{Notes}

(1) We referred to the last International Standard Classification of Education UNESCO 2011 according to which: ISCED $6=$ Bachelor or equivalent level degrees; ISCED $7=$ Master or equivalent level; ISCED $8=$ Doctoral or equivalent level;

(2) Since there is no an already established common classification for disciplines between Italian and English students, an ad-hoc classification has been built based on the possibilities given by the structure of the raw data. The 10 resulted disciplinary areas are: 1) Mathematics and physics; 2) Chemistry-pharmacy; 3) Geology and Biology; 4) Health; 5) Agriculture; 6) Engineering and Architecture; 7) Arts and Humanities; 8) Law; 9) Economics and statistics; 10) Politics and sociology;

(3) International students are here intended as those students that present a foreign residence at the moment of the enrollment. Foreign refers to both European and non-European countries;

(4) Since the number of new students enrolled for every year is not available for English universities, the number of unique applicants has been chosen to substitute this data.

(5) The number of English regions is based on the HESA classification of 11 regions whereas the Italian regions correspond to the 20 administrative recognized by the law. 
Dendrograms of cluster analyses for Italian HEIs (Section 4.2, Tabs. 3 and 4)
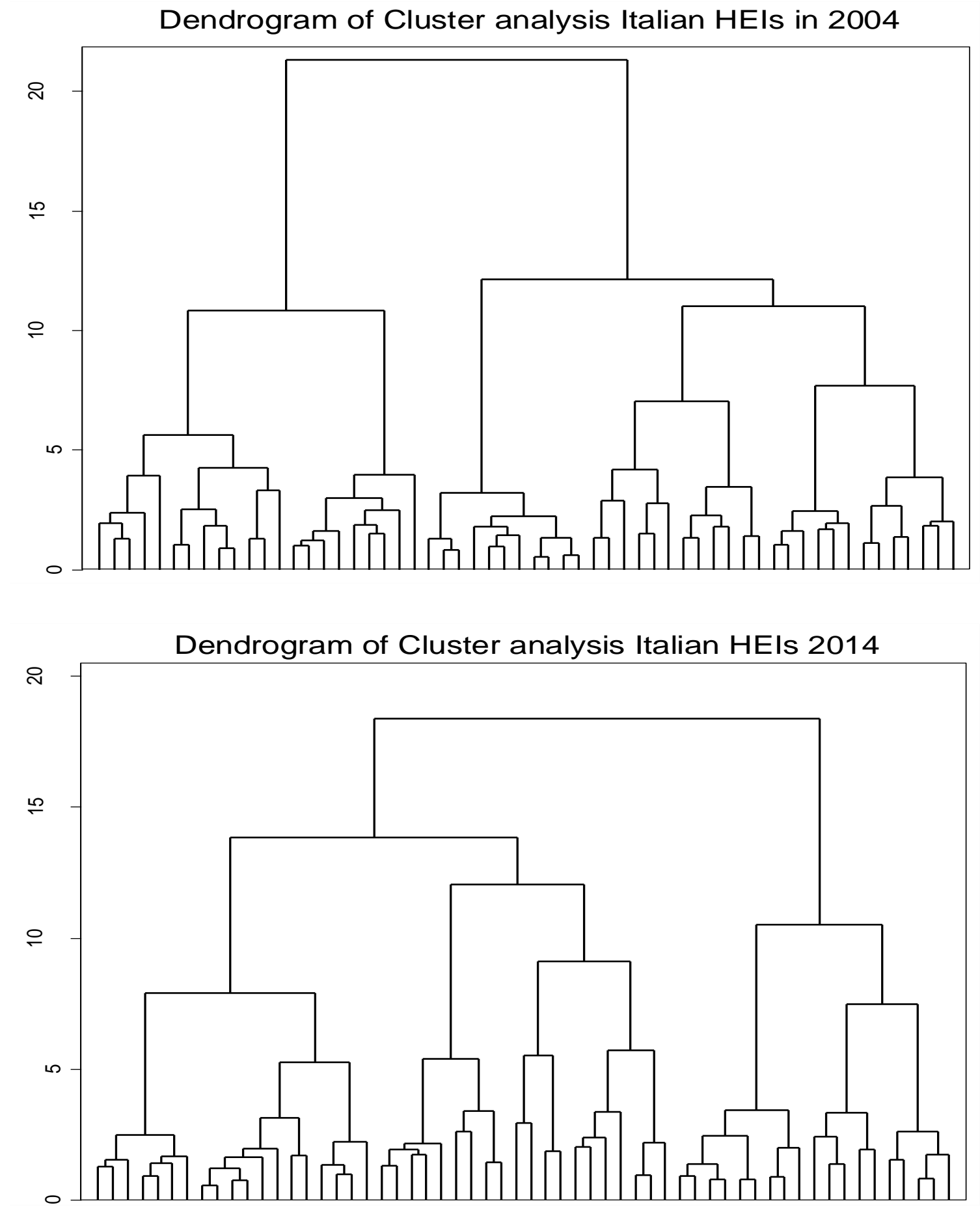
Dendrograms of cluster analyses for English HEIs (Section 4.2, Tabs. 5 and 6)
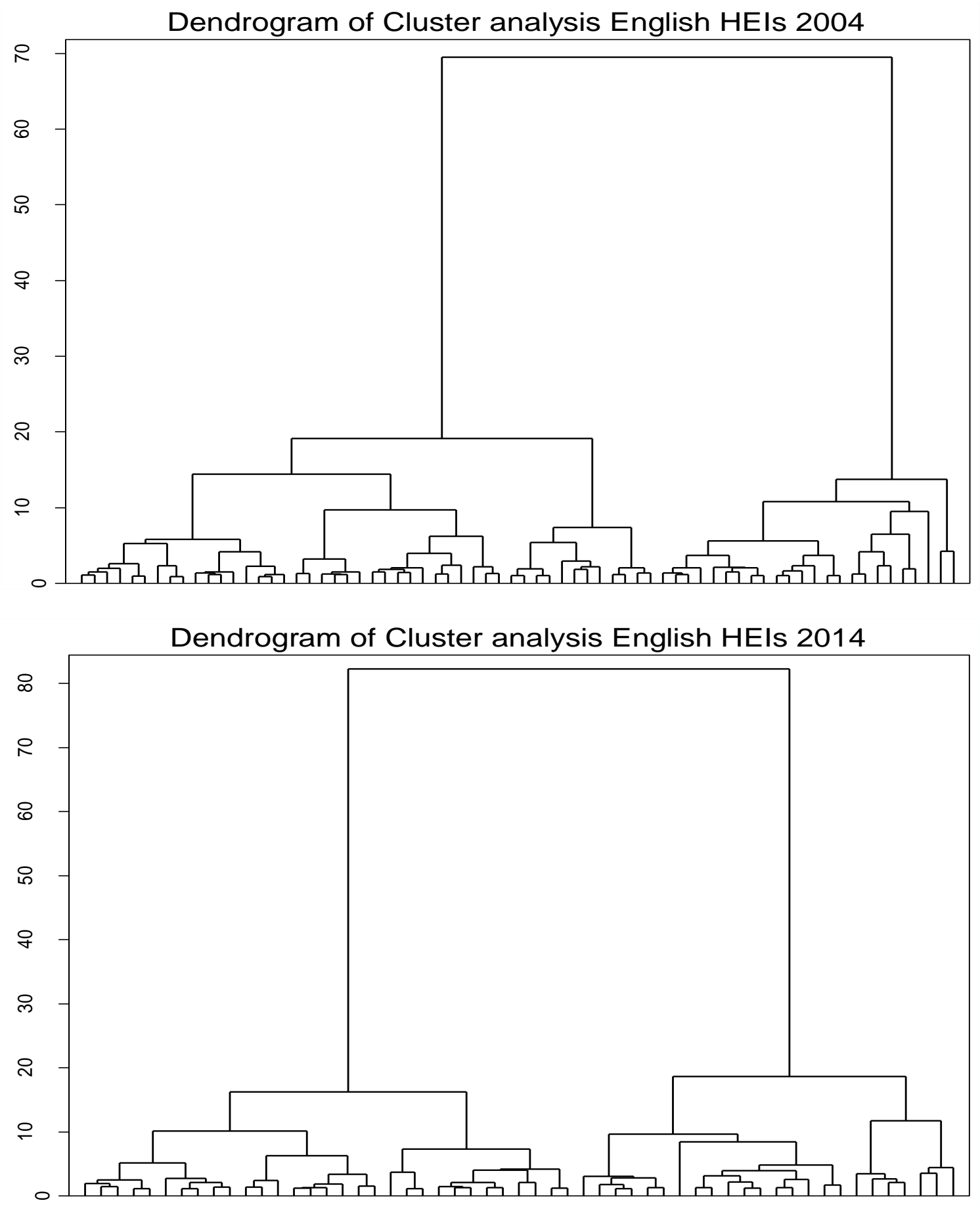